\title{
Journal Impact Factor (JIF): The Good, the Bad, and the Ugly
}

\author{
Jerzy W. Kupiec-Weglinski
}

Invited commentary

Kudos to Professor Edward Towpik, M.D., Ph.D., Editor-In-Chief of Nowotwory, for taking on the "IF-Mania". I was impressed by his comprehensive and thorough review of the relevant scientific literature. I am also grateful for his invitation to address the growing controversy on what the JIF should represent, and how it evolved. Below are some of my (personal) thoughts, based on over 35-year experience of working as a physician-scientist, first at Harvard University, Boston (1979-1997) and then at the University of California, Los Angeles (1997-present).

First, to set up the stage, we need to recognize that IF was conceived by Eugene Garfield to evaluate science and social science journals per se [1]. However, IF became a measure and symbol of the scientific prestige and relevance, while all comparisons were supposed to include journals rather than individuals. It soon became clear that only journals dedicated to the same scientific specialty must be compared because the value of the IF varies greatly between the disciplines. As an example from my own field, the IF of the most "prestigious" surgical journal, Annals of Surgery, equals 8.327, versus IF of 21.561 attached to the "best" immunology journal, Immunity. More, if you are a plastic surgeon, the IF of a top journal you dream of publishing your research, Plastic and Reconstructive Surgery, is 2.993. Can we really compare "apples and oranges"? I have no doubt that impact factors are important for journal's editors, and I happen to be one of them (Current Opinion in Organ Transplantation; IF $=2.880$ ). However, the idea that impact factors in any way reflect the quality or reliability of the science, or the ability and creativity of a scientist, may be misleading. On the other hand, most esteemed journals, such as New England Journal of Medicine (IF = 55.873); Lancet (IF = 45.217) or Annual Reviews in Immunology (IF = 39.327) have always been and most likely will remain top science journals for years to come. I tend to believe, against the critiques, that a journal with high reputation is an appropriate (or even preferable) vehicle to assist a scientist, especially a young one, in exposure of his or her research. Certainly, there are plenty of high impact papers that are published in low-impact journals and vice-versa. Most important is to publish good quality and innovative science and to have a record of continuous publications and productivity.

Another example, from my field, is of a brilliant scientist who may suffer a "heart attack" by focusing his publication choices solely at JIF. In 2010, many high quality manuscripts were submitted for publication in Cell Transplantation, $\mathrm{IF}=6.204$. One year later, the journal had been dropped from Journal Citation Reports (JCR) and had no IF at all (current $\mathrm{IF}=3.127$ ). Obviously, those who published high quality papers in 2010 in Cell Transplantation (and other journals where IF changed drastically) were in total loss in 2011. Needless to say, IF-mania associating the value of research with the journal where the work is published, may distort the way science is conducted. Moreover, JIFs are often influenced by positive feedbacks with citations not based on the reading the paper itself but by reading other papers, primarily reviews. Some even claim that there is a "positive" correlation between the rate of paper retraction and JIF.

According to Eugene Garfield, out of 38 million articles published from 1900 to 2005, half were never cited, whereas only $0.5 \%$ was cited more than 200 times [2]. For good or for bad, citations are important as they reflect as to whether and how published science resonates and moves the field forward. Let's be honest, there is a lot of bad science around, which should have never been published, at the first place.

In the last 20 years or so, the citation fishing and citation-bartering became major pursuits on both sides of the Atlantic. Based on my observations, I do believe the pernicious effects of IF-mania are benign as compared to the European scene. As a Vice-Chair for Research in the Depart- 
ment of Surgery at UCLA, the largest solid organ transplant center in the country, I keep my mind open that I am not hiring or evaluating a "number" but a person with a mix of abilities, of which, in the research field, the originality is the most important. The question then arises whether "originality" can be measured by the JIF or past citations? In the current economic climate, with shrinking federal research budget and $\mathrm{NIH}$ grant success at all-time low of about $10 \%$, we do need "metrics" to objectively evaluate grant applications. This is a demanding and frustrating task as the process may affect many careers. Obviously, innovative research plan, supported by solid preliminary data, is of utmost importance for the ultimate success. However, we, the reviewers need also to look carefully where the applicant comes from, i.e., what is his/her publication record. Clearly, papers published in "top-tier" journals will impress and make the proposal more legitimate as compared with publications in low impact or no IF journals. It's worth mentioning that the most recent $\mathrm{NIH}$ bio-sketch revision requires the applicant to outline up to five his/her research areas of the highest "scientific impact". On a personal note, when I started my career at Harvard in the early 1980s, obviously "happy days" with no JIFs around, Transplantation, was our journal. Now, the very same journal (IF $=3.802)$ is one of many to attract our research. Needless to say, in the revised $\mathrm{NIH}$ bio-sketch, and despite many subsequent contributions in much higher IF journals, I do cite Transplantation papers from the 1980s on lymphocyte trafficking as one of the most impactful in my career.

Let me conclude by stating that high impact (factor) research became hot commodity that pays... First, we have too many journals, which charge too much for publishing scientific data. The higher IF of the journal, the steeper publication costs. Are you willing to spend over $\$ 2,000$ for 5 color prints and page charges to publish a paper in Gastroenterology (IF = 16.716)? I did and have to admit I was very pleased to do so, despite the price tag and months of hard work to address reviewers' critique. To make the long story short, that paper has led to the second and the third one (published in JIF of 10-12), ultimately resulting in $\mathrm{NIH}$ funding. I doubt I were equally successful if my research was published, for instance in Journal of Surgical Research (IF = 1.936). Obviously, the review process in a "prestigious" high impact factor journal is not trivial. It is a grueling experience as you are dealing with the highest caliber of your own, in most cases honest but tough, peers.

Pursuing research career nowadays (i.e., in the IF-mania era) is not easy, but let's be realistic, IFs do influence the reputation of researchers and will influence their careers for years to come. Perhaps, $\mathrm{H}$-index, which measures the total number of papers a scientist has authored and the number of citations those papers have received, may be more acceptable to some. If, over a lifetime of a research career, you have authored 50 papers that have been cited 50 or more times, your $\mathrm{H}$-index $=50$. This measure should satisfy most of malcontents, as it relates to the papers, which are cited over years, even if published in journals with low IF. The bottom line is, you need to publish research that is reproducible, impactful and moves your field forward. And remember, you have to impress your peers to read your publications and cite your discoveries!

Jerzy W. Kupiec-Weglinski, M.D., Ph.D.

Joan S. and Ralph N. Goldwyn Chair in Immunobiology and Transplantation Research

Professor of Surgery, Pathology and Laboratory Medicine

Director, Dumont-UCLA Transplantation Research Center

Vice-Chairman (Research), Department of Surgery

David Geffen School of Medicine at UCLA

członek zagraniczny

Polskiej Akademii Nauk

i Polskiej Akademii Umiejętności

\section{References}

1. Garfield E. Citation indexes to science: a new dimension in documentation through association of ideas. Science 1955; 122: 108-111

2. Garfield E. The history and meaning of the journal impact factor. JAMA 2006; 295: 90-93. 